\section{In Arbeit: S2k-Leitlinie zur Autoimmunhepatitis}

Derzeit entwickelt die Deutsche Gesellschaft für Verdauungs- und Stoffwechselkrankheiten (DGVS) eine S2k-Leitline "Autoimmune Lebererkrankungen“. Sie bringt einige Neuerungen mit sich, die den Umgang mit Patienten im Praxisalltag erleichtern. So werden Anforderungen an die serologische (Autoantikörper-)Diagnostik konkret definiert, aber auch Empfehlungen für Impfungen sowie Hinweise auf Besonderheiten bei der Versorgung von Kindern gegeben, erläuterte Prof. Dr. Christian Strassburg,
Bonn. Neu aufgenommen wurden IgG4assoziierte Erkrankungen.

\section{Budesonid als Alternative für Patienten ohne Zirrhose}

Konkretisierungen gab es auch in der Therapie der Autoimmunhepatitis. Sie stützt sich nach wie vor auf die Kombination von Azathioprin und Prednisolon. Als Alternative für Patienten ohne Leberzirrhose wird Budesonid (z.B. Budenofalk ${ }^{\circ}$ ) empfohlen. Vorteil des topischen Steroids ist sein hoher First-

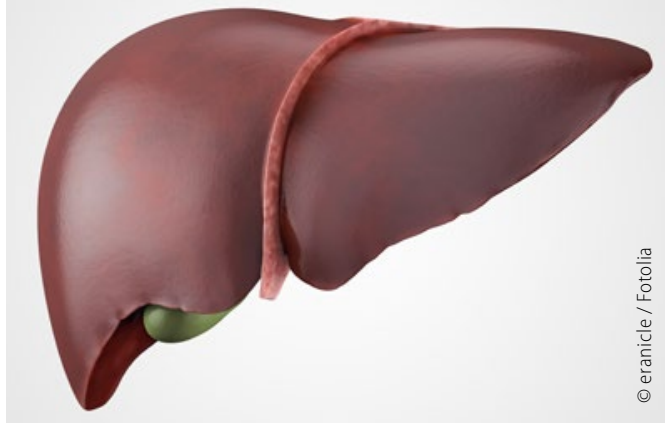

pass-Effekt, durch den sich das Risiko steroidspezifischer Nebenwirkungen deutlich reduziert. "Ich halte das für eine wichtige Korrektur der Leitlinie“, so Strassburg. Er betonte, dass nicht nur bei jungen Frauen mit erhöhten Leberwerten an eine AIH gedacht werden sollte, sondern durchaus auch bei älteren Männern.

(BF)

22. Symposium Aktuelle Hepatologie 2016: das Leben nach Hepatitis C (Veranstalter: Falk Foundation e. V.), Mannheim 9. April 2016

\section{Die Forschung trägt Früchte}

\section{Neuer Hoffnungsträger bei PSC in Sicht}

Die primär sklerosierende Cholangitis (PSC) gilt bislang als die „black box“ in der Hepatologie. Die Prognose ist schlecht mit einem erhöhten Risiko für chronisch entzündliche Darmerkrankungen, Cholangio- und Kolorektalkarzinom sowie einem transplantationsfreien Überleben von etwa 20 Jahren, so Prof. Dr. Ulrich Beuers, Amsterdam. Das Problem: Ein wirksames Medikament steht nicht zur Verfügung. Auch Ursodesoxycholsäure (UDCA), die Standardtherapie bei primär biliärer Cholangitis, schlägt fehl. Deshalb sei es wichtig, mögliche Differenzialdiagnosen, die gut behandelbar sind, konsequent abzuklären, wie etwa eine IgG4-assoziierte Cholangitis. Doch die Forschung der letzten Jahre im Bereich der PSC hat laut Prof. Dr. Michael Manns, Hannover, inzwischen Früchte getragen: „Für norUDCA konnten aktuell vielversprechende Ergebnisse einer Phase-II-Studie vorgestellt werden, die einen Hoffnungsschimmer für die $\mathrm{Pa}$ tienten bedeuten."

\section{Alkalische Phosphatase im Serum signifikant reduziert}

In der multizentrischen, randomisierten und plazebokontrollierten Phase-II-Studie, die auf dem diesjährigen Internationalen Leberkongress (EASL) in Barcelona präsentiert wurde, konnte mit norUDCA bei Patienten mit PSC die alkalische Phosphatase im Serum (s-AP) signifikant reduziert werden. Insgesamt wurden 159

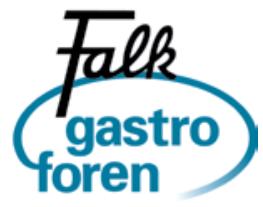

Besuchen Sie das nächste Falk Gastro Forum "Viszeralmedizin heute: Von der Empirie zur personalisierten Medizin" am Samstag, den 4. Juni 2016 in Essen; Infos: www.drfalkpharma.de/veranstaltungen
PSC-Patienten über zwölf Wochen entweder mit nor-UDCA in Tagesdosen von $500 \mathrm{mg}, 1000 \mathrm{mg}$ oder $1500 \mathrm{mg}$ behandelt, oder mit Plazebo. Mit Erfolg: Unter $1500 \mathrm{mg}$ norUDCA reduzierte sich der s-AP-Spiegel im Vergleich zum Ausgangswert um $26 \%$ und unter norUDCA 1000 mg um 17,3\%. Dagegen kam es unter Plazebo im gleichem Zeitraum zu einem Anstieg um 1,2\% - ein signifikanter Unterschied. Doch nicht nur der primäre Endpunkt wurde erreicht. NorUDCA zeigte sich auch mit Blick auf die sekundären Endpunkte überlegen, wie etwa der Verbesserung der Transaminasen und dem Anteil an Patienten mit s-APSerumspiegeln $<1,5$ ULN am Ende der Therapie. Nebenwirkungen waren insgesamt selten und lagen auf Plazeboniveau.

Die Studie zeige, dass norUDCA eine wertvolle Behandlungsoption für Patienten mit PSC sein könnte, die sicher und effektiv zu sein scheint, so Studienleiter Prof. Dr. Michael Trauner, Wien, der die Daten auf dem EASL präsentierte. 